\title{
EFICIENCIA DE LA SEMILLA DE ALGODÓN EN EL INCREMENTO DE SÓLIDOS TOTALES EN LA LECHE DE ORIGEN BOVINO. \\ CAYAMBE - ECUADOR
}

* Luis Nepas

** Hans Beltuán

\section{INTRODUCCIÓN}

Cinco comunidades de la zona norte del cantón Cayambe en la provincia del Pichincha se encuentran equipadas con centros de acopio y enfriamiento de leche, negociando juntas un total de 9000 litros diarios a la empresa Nestlé, ubicada en la ciudad de Cayambe. Esta empresa establece sistemas de pago en base a dos parámetros de calidad: horas de reductasa y sólidos totales. Debido a la tecnología de frío (tanques de enfriamiento) las horas de reductasa conseguida promedia las 5.5, dejando un margen de apenas 0.5 horas para llegar a lo óptimo (6 horas). En contraste a esto, el porcentaje de sólidos totales obtenidos en los centros de acopio promedia el $12.30 \%$, valor bajo, si la tabla de pagos registra un precio tope con $13.15 \%$ de sólidos totales.

La vía directa que permite incrementar sólidos totales en la leche es la alimentación. Es así que se decidió probar pepa de algodón en la dieta alimenticia diaria del ganado bovino. La pepa de algodón es un alimento de características únicas, ya que ningún otro alimento para rumiantes tiene concomitantemente altos valores de energía, proteína y características tan interesantes para su fibra. La utilización de semilla de algodón en vacas en lactancia aumenta la producción de leche y el contenido de grasa y por ende el porcentaje de sólidos totales, ya que cierta proporción de la grasa de la semilla de algodón es transferida directamente a la grasa de la leche.

El gráfico muestra claramente los porcentajes de cada uno de los componentes de la semilla de algodón, por lo que se puede definir como un producto único que sirve para la sobrealimentación de los bovinos.

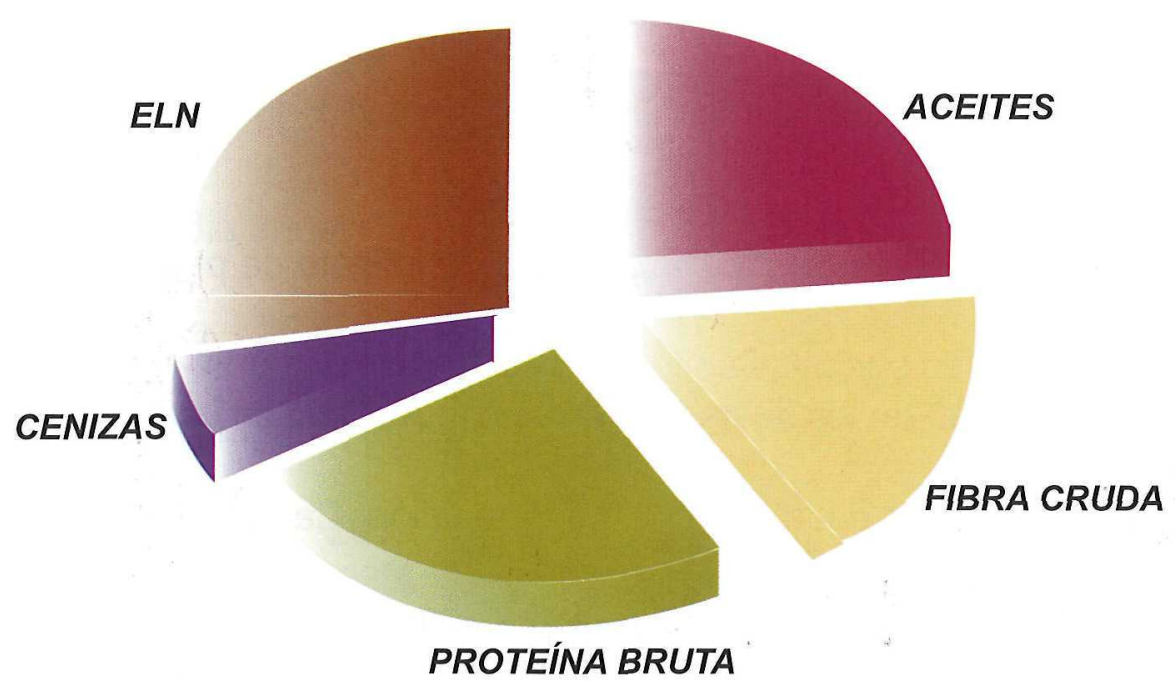

COMPOSICIÓN DE LA SEMILLA DE ALGODÓN (BASE 100\% SECA) 


\section{PROCEDIMIENTO}

Se utilizó un DBCA con dos repeticiones y cuatro tratamientos, que consistieron en suministrar $0 \%, 0.1 \%, 0.08 \%$ y $0.06 \%$ de pepa de algodón diariamente, en base al peso vivo de los animales. La determinación del contenido de sólidos totales en la leche se la realizó a través de la fórmula de Richmond, con la determinación previa del contenido de porcentaje de grasa a través del método Gerber y la densidad de la leche con la ayuda de un lactodensímetro tipo $\mathbf{E}$.

\section{RESULTADOS}

Del análisis de varianza se desprende que para tratamientos no existe significancia estadística, pero a pesar de esto, si se observa el promedio de tratamientos se obtiene incrementos de sólidos totales de alrededor de $0.3 \%$. Es importante indicar, que la literatura revisada sobre efecto de la pepa de algodón en el incremento de sólidos totales registra dosis diarias de hasta $5 \%$ en base a peso vivo del animal, pero a pesar de esto, se decidió suministrar tratamientos con dosis no mayores que $0.1 \%$ del peso vivo. La razón radicó básicamente en el hecho de que no se encontró literatura en nuestro país sobre el tema, y si se considera que la semilla de algodón contiene un compuesto denominado gosipol, que es particularmente tóxico para monogástricos, pero que es destruido en proporciones desconocidas a nivel ruminal, los animales corrían peligro de sufrir intoxicaciones.

Con estos resultados se volverá a repetir el proceso experimental con tratamientos que incluyan dosis de pepa de algodón mayores al $0.1 \%$ del peso vivo, con la seguridad de no causar daño a los animales.

\section{BIBLIOGRAFÍA}

- WEYNULS, C.: Pastos, forrajes y alimentación para rumiantes, cap.6, págs. 22-24.

- VARGAS OSORIO. Actividades socioeconómicas vinculadas a las variaciones microclimáticas en la subcuenca del río la Chimba, cantón Cayambe.

- VALENCIA, César: Módulo de industrias lácteas №2. Biblioteca de la Universidad Politécnica Salesiana, Cayambe.

- CENTROS DE ACOPIO Y ENFRIAMIENTO DE LECHE de las Comunidades la Chimba, Pesillo, el Chaupi, Paquistancia y Santo Domingo $n^{0} 1$ - Cayambe-Ecuador - www. Portal veterinario. com

\footnotetext{
* Tesista de ingeniería agropecuaria-Cayambe.

** Catedrático de Bovinotecnia. Director de tesis.
} 